\title{
(Um) Currículo cultural contrassexual? Movimentos que possibilitam corpos em trânsito
}

\section{(One) Countersexual cultural curriculum? Movements that enable bodies in transit \\ (Un) ¿Currículo cultural contrasexual? Movimientos que habilitan cuerpos en tránsito}

Cyndel Nunes Augusto ${ }^{a}$ (D) , Marcos Garcia Neirab* (D)

Palavras-chave

Educação Física;

Currículo cultural;

Gênero;

Sexualidade.

\begin{abstract}
RESUMO
$\mathrm{O}$ artigo analisa 12 relatos de experiências desenvolvidas por docentes que afirmam colocar em ação o currículo cultural de Educação Física e que descrevem situações envolvendo as relações de gênero e sexualidade. Os documentos foram confrontados com os argumentos disponíveis nas obras de Judith Butler e Paul Beatriz Preciado. Tendo por objetivo pensar em possibilidades de um currículo cultural contrassexual, infere-se a relevância de uma escrita curricular que não seja prescritiva, mas que parta do próprio fazer docente para propiciar a explosão de novos significados.
\end{abstract}

\section{Keywords}

Physical Education;

Cultural curriculum;

Gender;

Sexuality.

\begin{abstract}
This article analyzes 12 reports of experiences developed by teachers who claim to put into practice the cultural curriculum of Physical Education, which describe situations involving the relations of gender and sexuality. The documents were compared with the arguments available in the works of Judith Butler and Paul Beatriz Preciado. Aiming to think about the possibilities of a countersexual cultural curriculum, we can infer the relevance of a nonprescriptive curriculum writing, but starting from the teaching profession itself to provide an explosion of new meanings.
\end{abstract}

\begin{abstract}
RESUMEN
Este artículo analiza 12 relatos de experiencias desarrolladas por docentes que pretenden poner en práctica el currículo cultural de Educación Física, que describen situaciones que involucran las relaciones de género y sexualidad. Los documentos se compararon con los argumentos disponibles en las obras de Judith Butler y Paul Beatriz Preciado. Con el objetivo de pensar en las posibilidades de un currículo cultural contrasexual, podemos inferir la relevancia de una escritura curricular no prescriptiva, pero partiendo de la propia profesión docente para brindar una explosión de nuevos significados.
\end{abstract}

\section{Palabras-clave} Educación Física; Currículum cultural; Género;

Sexualidad.

\footnotetext{
aUniversidade de São Paulo, Faculdade de Educação, Programa de Pós-graduação em Educação. São Paulo, SP, Brasil.

'Universidade de São Paulo, Faculdade de Educação, Departamento de Metodologia do Ensino e Educação Comparada, Programa de Pós-graduação em Educação. São Paulo, SP, Brasil.
}

*Autor correspondente:
Marcos Garcia Neira
E-mail: mgneira@usp.br
Recebido em 2 de junho de 2021; aceito em 9 de junho de 2021.
DOI: https://doi.org/10.1590/rbce.43.e002221 


\section{PRÓTESES CURRICULARES: COM- POSIÇÕES DA ESCRITA}

Os estudos curriculares reconhecem a emergência de propostas comprometidas com a formação de sujeitos solidários. Em linhas gerais, afastam-se da preocupação com a seleção e a organização de conhecimentos ou da mera denúncia sobre as formas de controle empreendidas pela escola capitalista para contemplar saberes de variados matizes em busca da afirmação das diferenças. Apesar do amplo gradiente de referenciais que configuram suas epistemologias, esses estudos têm como ponto comum a centralidade na cultura e a relevância atribuída à linguagem como produtora da realidade.

No âmbito da Educação Física, essas influências se fazem notar na teoria curricular cultural. Enquanto, nos anos iniciais deste século XXI, os primeiros experimentos com a proposta receberam contribuições do multiculturalismo crítico e dos estudos culturais, na atualidade outras formas de análise do social, como o pósestruturalismo, o pós-colonialismo, os estudos de gênero e a teoria queer, têm inspirado os encaminhamentos pedagógicos de docentes que afirmam colocar em prática essa perspectiva curricular.

Rocha et al. (2015) identificam na produção do Grupo de Pesquisas em Educação Física Escolar (GPEF), da Faculdade de Educação da Universidade de São Paulo (USP), um contingente representativo de pesquisas com a pedagogia cultural do componente. O coletivo mantém um repositório com mais de 150 registros escritos de experiências realizadas com a proposta. Dos 17 relatos publicados em 2019, 12 descrevem episódios em que docentes e estudantes problematizam relações de gênero e sexualidade durante a tematização de diferentes práticas corporais. O presente estudo emprega a argumentação elaborada por Judith Butler e Paul Beatriz Preciado para pensar em possibilidades de um currículo cultural contrassexual.

\section{TECENDO HISTÓRIAS E REFLEXÕES}

Mesmo se afugentando, as experiências dançantes imprimiam em seus corpos uma série de desejos cruzados a cada som tocado. Algumas crianças preferiram permanecer sentadas nas cadeiras, aprisionadas às carteiras, na condição de observadoras e comentadoras. Nos devires da dança, narrativas foram proclamadas: "menino não rebola", "mexe a raba", "os meninos vão querer sarrar as meninas", "esse movimento só os meninos vão conseguir fazer", "não sou menina, não vou dançar". Esses enunciados nos levaram a tematizar o funk na tentativa de problematizar esse corpo que rebola, desce e sobe, vai até o chão, pula, retrai-se, desliza, faz quadradinho, canta e grita. (Relato $01^{1}$, p. 4).
Um corpo, matéria que tem potência disforme e teima rigidez e formato. Imposições que chegam antes mesmo do nascimento em uma materialidade sempre dual. Um corpo que toma forma a cada palavra lançada ao vento: palavra que é matéria, que impregna nos poros e cria um corpo homem e um corpo mulher, corpo contido. Corpo esse que se faz em ação, em repetição, em constância e todo dia. Não é somente reprodução do que se vê, é produção e manutenção de um cenário que privilegia alguns, violenta outros e molda todas/os. E se ousar escapar, a violência atravessa, chega pelo verbal, pelo psicológico, pelo físico. Chega na tentativa de (re)organizar um corpo fugitivo, um corpo que ousa sair da linha, um cenário que desestabiliza, tenta (re)instaurar a suposta ordem.

A mesma [diretora] expôs uma situação que se passara no dia anterior: um pai, bastante enfurecido, foi à escola questionar os motivos pelos quais seu filho estava brincando com bonecas nas aulas de Educação Física. Disse ter queimado a Abayomi feita pelo menino, na sua frente. Com o tom de voz elevado e batendo sua mão sobre a mesa, buscou intimidar a diretora, lançando inclusive algumas ameaças. A diretora tentou, sem sucesso, explicar o trabalho para o pai, e defendia as problematizações realizadas. Entretanto, ele se recusava a escutar. Quando sua esposa, que também estava presente, tentava proferir algumas palavras sensatas, era interrompida pelo marido de forma ofensiva. O pai se retirou da escola, ainda bravo, sem assinar o livro de ocorrências, e seu filho entrou na sala de aula chorando. (Relato $02^{2}$, p. 4-5).

Um corpo criança que sente interesse no novo, que se envolve pela proposta, que antes proferia a certeza de uma brincadeira somente de menina e que foi levado pelo brincar com a boneca feita por ele. A voz que chega interdita esse corpo brincante que desloca momentaneamente o sentido dual menina-menino; a voz que ecoa os sentidos já tão presentes na sociedade; a voz que reafirma que as coisas têm lugar e que não podem simplesmente ser modificadas. A voz alta quer endurecer o sentido e grita quando percebe que isso não é possível. Ao cruzar o portão da escola, a criança se encontra com o desconhecido, com a possibilidade, com o Outro que transforma. É no entrar na sala de aula que vem a segurança, mesmo que fugaz, em ter um corpo que pulsa outros sons, ritmos, olhares, viveres. E a voz raivosa continua a gritar, na tentativa de manter o território normativo que lhe era tão natural, mas, do portão para dentro, algo (de novo) acontece.

Quando dizemos que o gênero é provocado por normas obrigatórias que nos demandam sermos um gênero ou outro (geralmente dentro de um quadro estritamente binário), estamos apenas dizendo que qualquer negociação com o gênero é uma negociação de poder. Não existe um gênero ontologicamente

1 Ver Torres et al. (2019).

2 Ver Irias (2019). 
fixo, e mesmo aqueles que parecem fixos, têm de ser fixados mais de uma vez, todos os dias, todas as noites, para dizer o mínimo. Assim, sugiro que não há gênero sem essa reprodução de normas que corre o risco de desfazer e refazer as normas dominantes de maneiras inesperadas, abrindo a possibilidade de refazer a realidade de gênero diante de novas linhas. Deste modo, o gênero é contínuo, aberto à revisão, em risco para um futuro diferente. Isso faz a diferença quando consideramos quais intervenções podemos fazer para o futuro do gênero. (Butler, 2017, p. 37-38).

Insistência. Quantas palavras moldaram aquele corpo-homem-pai que não quer permitir que o corpomenino-filho tenha qualquer aproximação com o feminino? Quantas imagens, quantos sons, quanto foi investido dessa maquinaria biofarmacopolítica para criar um corpo prostético que regozija a (suposta) masculinidade e virilidade? Próteses atrás de próteses são acopladas ao corpo em uma tentativa (falha) de interditar os movimentos resistentes. Um gênero que se faz se fazendo, um fazer que fixa e que transfigura. "Não somos presos, então. Acontece que estamos sempre de acordo com a situação. O que quero dizer é que temos a possibilidade de mudar a situação, que esta possibilidade existe sempre" (Foucault, 2004, p. 267).

Uma batida pulsa em cada sujeito, uma batida que arrebata, que desmonta, que desloca, que destrói, que implode e que explode, ritmo que pulsa, que gera trânsito, que se repete para mostrar que nada fica igual. Um impulso, semente que cresce; uma chama que espreita astuta a força que a convoca, aguardando para arrastar e alastrar os diversos significados. Não se sabe de onde vem, se é de fora, de dentro, de todos os lados ou lado algum. Só surge, às vezes longa, às vezes curta, às vezes lenta, às vezes rápida e repetidas vezes; outras, vem e vai em um piscar de olhos. É efêmero, pois se desmonta no momento seguinte e a partir de um jogo outro de forças em movimento. Impossível separar a força que atravessou esse momento e o transformou em potências outras. Impossível separar o que aprisiona do que é linha de fuga, possibilidade, alternativa. Mas está ali, acontecendo, em movimento. Os corpos flutuam e circulam em meio a esse emaranhado confuso e disforme de dúvidas, anseios, deslocamentos e fixações. Tudo ocorre em um jogo de forças. Nada acontece fora, não existe o fora. No momento mesmo em que o pai grita, a criança desloca os sentidos, e, na tentativa de restaurálos, a escola cria novos movimentos de deslocamento. No encontro com as demais crianças, que também estão no jogo, as forças se cruzam e se distorcem; não se sabe o que pode surgir, mas que, de algum modo, transforma a situação. É a partir da ação didática, do olhar sensível com o momento e com a enunciação de saberes e desejos discentes, é a partir da possibilidade de artistagem do professorado que as forças ganham passagem.

Eis que as aulas vão acontecendo, os meses vão passando e por conta de uma reforma na escola a festa junina foi adiada e transferida para o mês de agosto. Até lá, continuaram estudando $k-p o p$, mas com a participação cada vez menor dos meninos que insistiam que $k$-pop era coisa de menina e que o ideal era ter aula livre ou futebol. Em uma das ocasiões, enquanto alguns meninos dançavam e participavam da coreografia, outros disseram que eles estavam dançando gay-pop. A partir daí, deu-se uma enorme confusão, brigas, eles se sentindo ofendidos por terem sido chamados de gays, outros incomodados com a tematização. Depois de muita conversa, o professor insistiu na necessidade de permanecer com o tema do $k$-pop, pois ainda não tinham estudado com densidade essa prática corporal e nem experimentado as diferentes formas de se dançar o ritmo. Os alunos já não ligavam quando eram provocados por aqueles que queriam futebol, ainda retrucavam chamando os demais de homofóbicos quando isso acontecia. (Relato $03^{3}$, p. 6).

A proposta contrassexual no currículo cultural é produzida no cotidiano, no fazer docente, em cada situação didática que semeia o incômodo, em cada possibilidade de suscitar a multiplicidade de sentidos e possibilidades de experimentar, criar e viver o corpo, o gênero e a sexualidade. É uma proposta de jogar-se no duvidoso, nas perguntas, no que é contraproducente. É a tentativa radical de uso outro do corpo que denuncia a ficcionalidade de uma suposta natureza, que escancara o caráter prostético daquilo que é imposto como natural, que produz uma contradisciplina sexual:

A contrassexualidade não é a criação de uma nova natureza, pelo contrário, é mais o fim da Natureza como ordem que legitima a sujeição de certos corpos a outros. [...] a contrassexualidade aponta para a substituição desse contrato social que denominamos Natureza por um contrato contrassexual. No âmbito do contrato contrassexual, os corpos se reconhecem a si mesmos e reconhecem os outros corpos como falantes. [...] Por conseguinte, renunciam não só a uma identidade sexual fechada e determinada naturalmente, como também aos benefícios que poderiam obter de uma naturalização dos efeitos sociais, econômicos e jurídicos de suas práticas significantes. (Preciado, 2017, p. 21).

É uma ação política do corpo. Uma proposta prostética, de intervenção no e do corpo, "hackeadora" do sistema, que prioriza o acontecimento, que não busca coerência, que está sempre in transe, em trânsito, em movimento. É uma proposta de arquitetura outra desse corpo falante, ironicamente parodística. São suplementos que descentram o corpo. É sobre uma experiência estilística do viver que permita a multiplicidade. É sobre as micropolíticas. É sobre tudo e, talvez, sobre nada.

Talvez estas são algumas das questões que as alianças queer devem continuar a se perguntar: Como a

\footnotetext{
3 Ver Bonetto (2019a).
} 
população indizível fala e faz suas reivindicações? Que tipo de perturbação é esta dentro do campo de poder? E como essas populações podem reivindicar o que elas exigem para persistir. (Butler, 2017, p. 45).

Um currículo é disputa de poder, é terreno de luta, de contestação. É luta por validação, é tensão, é brigar por fazer ecos e manter silêncios. O currículo cultural, por sua vez, pretende interromper tais silêncios, fazendo as vozes chegarem mais longe, fazendo emergirem corpos outros, os quais a sociedade tenta apagar, tenta marginalizar. "Uma educação intercultural apropria-se dessa perspectiva e promove outras narrativas nas quais as vozes que nunca tiveram o poder de narrar possam ocupar, mesmo que temporariamente, uma condição de hegemonia cultural" (Neira e Nunes, 2009, p. 277). Agenciando docentes com os princípios ético-políticos de reconhecimento do patrimônio cultural corporal da comunidade, justiça curricular, descolonização do currículo, ancoragem social dos conhecimentos, favorecimento da enunciação dos saberes discentes e rejeição ao daltonismo cultural, o currículo cultural desloca as vertentes fundadas na psicobiologia que marcaram a história da Educação Física, trazendo à baila fatores políticos, históricos, sociais, culturais, econômicos, entre tantos outros recortes possíveis que moldam a educação e o fazer docente. Sem configurar etapas ordenadas previamente, as situações didáticas abarcam o mapeamento, vivência, leitura da prática corporal, ressignificação, aprofundamento, ampliação, registro e avaliação (Oliveira e Neira, 2020). Há um dinamismo infinito nessa escrita-currículo e seus múltiplos caminhos, sem prescrições e fórmulas, entendendo a construção do gênero como performática (Bonetto e Neira, 2019). "Assim como as superfícies corporais são impostas como o natural, elas podem tornar-se o lugar de uma performance dissonante e desnaturalizada, que revela o status performativo do próprio natural" (Butler, 2016, p. 252).

Nesta fluidez e transações de experimentações, cada um, ao seu modo, colocava em cena suas interpretações e produções gestuais. "Olha isso aqui". "Você nem sabe". "Sei sim". Os desafios seguiram constantemente, mostrar as inovações e criações eram tarefas de fundamental importância. Alguns corpos preferiram apenas observar. "Dança aí". "Eu não". "Olha como é fácil". Após o insistente chamado, umas permaneceram visualizando as colegas, enquanto outras se embebedaram do êxtase das batidas do funk, dos gestos e risos dos colegas e passaram a se arriscar na dança. (Relato $04^{4}$, p. 21).

Esses corpos-ação dançantes se constituem na relação. A partir das operações de reconhecimento do conjunto de cenas e tecnologias que permitem que esses corpos desejantes tenham sido vistos, explicitados, exteriorizados, é possível estabelecer alianças com outras

4 Ver Santos e Quaresma (2019). linguagens e outras performances capazes de construir a verossimilhança e as condições para que esses corposfalantes sejam citados, reproduzidos, reconfigurados. Há permissibilidade para a vida pulsante, para o corpo vibrante, para a ação. Constrói-se um território onde as manifestações culturais geralmente não aceitas adentrem a escola, ali estejam; onde os corpos-funkeirosprostéticos possam expressar-se, explodindo a energia contida. Os saberes discentes são escutados, acolhidos e potencializados, fazendo emergir uma tematização que, em outras situações, seria interditada. Ao ver um corpo dançante, outros corpos dançantes se fazem presentes, com intensidades e tempos diferentes, sendo atravessados uns pelos outros das mais diversas formas.

$\mathrm{Na}$ aula seguinte, iniciamos perguntando às crianças quais times de basquete feminino conheciam, e elas responderam que já haviam assistido jogos dos times Bauru, Flamengo, Corinthians, São Paulo, Santos e Paulistano. Quando questionados/as sobre times de basquete do bairro, apenas duas crianças afirmaram conhecer pessoas que participavam de times com essa característica. Em seguida, assistimos parte do vídeo Rachão Basquete Feminino, em que mulheres de diferentes idades se reúnem para jogar basquete em uma quadra pública. Durante a assistência, algumas crianças elogiaram as atletas apresentadas, dizendo que elas jogavam muito bem. (Relato $05^{5}$, p. 24).

Não se trata de pensar somente em quais corpos estão em uma condição ou em outra, mas sim de entender como são produzidos em tais e quais condições. É desnudar essa maquinaria de um regime farmacopornográfico (Preciado, 2018) que produz mais e mais próteses para manter os corpos estáveis em determinadas zonas de poder. Entender como se constrói esse corpo-máquina-prostético que hierarquiza algumas vidas em detrimento de outras, por meio do diálogo, mas também pelo e no corpo. É fazer saltar aos olhos esse corpo dissidente, mostrando sua potência e sua existência. Permitir a bunda-funkeira movimentar a aula, abalando a arquitetura corporal disciplinadora. Construir um percurso de experiências com as bonecas, de um corpo lido de mulher jogando bola, de um corpo com deficiência realizando práticas corporais, de um corpo negro em toda sua potência criativa. É preciso contágio por meio do tato, do olfato, da visão. É preciso o corpo presente na escola, com a escola. É preciso presença, grito, eco, voz.

Na semana seguinte a bailarina compareceu à escola e se dispôs a conversar com todas as turmas. As crianças estavam extremamente ansiosas e para aumentar a excitação, ao entrar na sala, solicitava à convidada que esperasse na porta, enquanto as crianças queriam saber se ela viera ou não. Quando era chamada a entrar na sala, as crianças ficaram surpreendidas 
porque ela divergia totalmente dos estereótipos que foram anunciados nas aulas anteriores. A bailarina se chama Angélica, tem 24 anos, é baixa, gordinha e tem Síndrome de Down, as crianças ficaram encantadas com sua presença. (Relato $06^{6}$, p. 7).

Tem um gordo jogando; a maioria é negro; professor, os jogadores do basquete de rua também ganham salários? Por meio desses enunciados, tentamos compreender o basquete urbano como forma de resistência e luta de alguns grupos sociais, um processo que se deu através de vídeos com narrativas de praticantes e discutindo os resultados das pesquisas trazidos pelas crianças. (Relato $07^{7}$, p. 16).

Quando esse corpo, socialmente tomado como incapaz, é visto em ação, em suas múltiplas formas de criação, ele implode e explode os significados, criando uma zona de possibilidades e alternativas, mesmo que momentâneas. "Trazer os representantes das práticas corporais à escola pode levar os estudantes a tomarem contato com outros discursos a respeito dessas pessoas e suas vivências com as práticas corporais" (Neves e Neira, 2020, p. 11). Quando se pensa e se organiza o espaço escolar para que esses corpos dissidentes estejam presentes, quando se investe em políticas de acesso, é esse próprio corpo que mexe nas estruturas, materializando as fagulhas criativas que desnaturalizam certas normatizações. A arquitetura do corpo é política, bem como os discursos que o circundam e o moldam de maneira a ser lido como incapaz. O movimento é, então, de desnudamento dessa certeza fundante de corpos e vidas almejadas, em que a precariedade é compartilhada e as alianças são criadas. Aparição pública e alianças são estratégias que visibilizam corpos subalternizados, formas de desterritorializar, de estabelecer novas conexões e relações (de poder) que potencializam a vida. É por meio do e nesse corpo-arquivovivido que surgem novas condições de existência.

A composição do estudo foi aos poucos sendo alimentada pelas vozes que ecoaram durante a minha caminhada na escola, desde o início, na escolha do tema, identifiquei que duas alunas do 7o ano adoravam k-pop, qualquer dúvida que surgia sobre a dança, recorria a elas. Elas me ensinaram os códigos, as gírias e falaram sobre o preconceito que sofriam por gostar de meninas. Para elas, escutar k-pop era uma maneira de aliviar a alma, de esquecer a vontade de sumir e de amenizar a dor que sentiam por gostar de pessoas do mesmo sexo. Todos os dias elas subiam à quadra para se beijar. A turma recebeu as meninas com maior carinho. [...] As garotas oportunizaram um belo debate respondendo às diferentes perguntas sobre o tema. (Relato $08^{8}$, p. 6).

\footnotetext{
6 Ver Gomes (2019).

7 Ver Silva (2019).

8 Ver Neves (2019a).
}

Como fazer resistência a toda violência que atravessa os corpos? É possível a proposta radical de mudança social? Como seriam as estratégias de resistência no currículo cultural? "Não há pretensões com a macromudança social nem com a emancipação do pensamento" (Eto e Neira, 2017, p. 588). A análise é dos microcontextos, em que a comunidade se vê perpassada, naquele momento, por determinadas forças e relações de poder, criando situações e subjetividades. A atuação é no escancaramento das assimetrias que condicionam os sujeitos, produzindo contranormativas alternativas a uma forma de ser e estar no mundo que aprisiona a incerteza de um corpo sempre em construção. "[...] o corpo é, sempre, resultado provisório e inacabado" (Dornelles, 2012, p. 189).

As práticas contrassexuais permitem e instauram a desmontagem das certezas prévias inscritas nos corpos docentes e criam uma zona intempestiva.

[...] as meninas disseram que queriam lutar com os meninos e ninguém se opôs. Ao longo dos combates, tampouco foram emitidos comentários sobre o assunto. Meninas e meninos lutaram, meninas e meninas, e meninos e meninos, sem qualquer acontecimento que merecesse nossa atenção. (Relato $09^{9}$, p. 3-4).

Uma proposta contrassexual e um currículo cultural não almejam pensar nos problemas antes de serem visualizados. É uma proposta de (re)descrição de possibilidades que já existem, de criação de alternativas outras, de repetição que difere. É a sensibilidade para ver a falha performática e como potencializá-la.

Afirmar que o discurso é formativo não significa afirmar que ele origina, causa ou exaustivamente compõe aquilo que ele admite; em vez disso, significa afirmar que não existe nenhuma referência a um corpo puro que não seja, ao mesmo tempo, uma formação adicional daquele corpo. Nesse sentido, a capacidade linguística para se referir a corpos sexuados não é negada, mas o próprio significado de "referencialidade" é alterado. Em termos filosóficos, a afirmação constatativa é, sempre, em algum grau, performativa. (Butler, 2001, p. 210).

A contrassexualidade está no campo da experimentação. Não é uma mudança da ordem do utilitarismo. É um processo infinito, influenciado por microprocessos de subjetivação. O currículo cultural é sobre encontrar esse suplemento perigoso que corrompe os significados das práticas corporais. A prática corporal se torna, então, prostética: quando, por exemplo, aborda-se um tipo de futebol, e mais esse, e mais esse, e mais esse..., cria-se um futebol prostético e produz-se também com as crianças esse futebol prostético, pois tudo isso que acontece age sobre o próprio futebol, para além do que se pensa sobre o futebol. E é nesse movimento performativo, do fazer fazendo, da repetição,

9 Ver Santos (2019). 
que se cria e permite ser outra coisa, que se instauram e deformam sentidos, que as práticas, as vivências e as relações tomam outras direções.

O sujeito só pode resultar do agenciamento, da ordem dos afetos, e não daquilo que ele escolhe. Um agenciamento coletivo de tudo o que circula: corpos emergem, disputam, gritam, reverberam, gozam, deslocam-se, ressignificam-se, sempre imersos nas relações de poder. Quando se profere algo, quando se age, há potência e impotência. Mas quando se grita a impotência, permite-se que ela retorne ao seu plano em um movimento incessante. É sobre saber assumir também deslizes da prática docente, perceber quando se está pretendendo algo antes mesmo da enunciação discente. Assim, não é sobre a busca por sentidos, mas é a vivência do processo. $O$ atravessamento nesse momento, bem como o que vem depois, é sempre incerto.

Não seria legal ter como objetivo tratar as danças de forma mais geral, apresentando várias danças/ ritmos na mesma tematização? Talvez, uma a cada 2 aulas? Eles confundiram RAP com rock muitas vezes. As meninas levantaram a camiseta amarrando na gola para mostrar a barriga quando dançavam funk. Seria uma boa questão para se problematizar. Tudo isso foi amplamente debatido no GPEF. (Relato $10^{10}$, p. 3).

No meio dessas considerações infantis, não menos importante ou relevante que de outra sujeita com mais idade, surgiram afirmações que nos levaram para outro lugar, vieram como uma marretada, pondo tudo a desmoronar sobre nossas mentes e concepções. "Eu não danço porque os meninos 'bate' e 'olha' na nossa bunda". "É verdade, a gente já falou para você e você não fez nada". Essas falas nos desconsertaram, ou melhor, nos destruíram. As crianças novamente gritaram situações que não fomos suficientemente capazes de encarar da maneira como deveríamos. (Relato 04, p. 23-24).

A grande tarefa ética é, assim, pensar em manter vivas as perguntas, as dúvidas, que são em si um projeto de vida. As perguntas têm função de abertura. O currículo cultural é um currículo da incerteza do processo, do fim, do começo, mas é a certeza de deslocamento e de movimento.

As questões tencionaram desnaturalizar as concepções dos estudantes: o que significa qualidade de vida? Por que a gente sai de casa para fazer atividade física e entende que isso é importante para a nossa vida? Foi sempre assim? Como as pessoas se relacionavam com os seus corpos em outras épocas? Por que em outras épocas ter uma imagem corporal que hoje é tomada como "gorda" era status social e agora é objeto de preconceito? (Relato $11^{11}$, p. 13).

\footnotetext{
${ }^{10}$ Ver Bonetto (2019b).
}

${ }^{11}$ Ver Neves (2019b).
É a pergunta que também leva à avaliação das práticas docentes, e não à da aquisição de uma materialidade funcional e neoliberal do corpo-criança. É um contrato contrassexual, no auge da sua ironia contratual, que garante a tentativa do disruptivo, a reelaboração na falha e no tropeço, que se compromete com a democracia, com o corpo não domesticado, com a justiça. Foge da inclusão moral, mas cria, por meio da prótese, possibilidades outras de viver. É por intermédio da paródia prostética no corpo-matéria que se desconstrói o corpo-verdade que tem que ser alcançado. O currículo cultural é uma possibilidade de desconstrução desse corpo fabricado, amordaçado. São afecções que vêm de toda a parte, composição de corpos com outros corpos para possibilitar contágios.

E é certo que a paródia tem sido usada para promover uma política de desesperança que afirma a exclusão aparentemente inevitável dos gêneros marginais do território do natural e do real. Todavia, essa impossibilidade de tornar-se "real" e de encarnar "o natural" é, eu diria, uma falha constitutiva de todas as imposições do gênero, pela razão mesma de que esses lugares ontológicos são fundamentalmente inabitáveis. (Butler, 2017, p. 252).

O corpo em paródia é uma categoria política. As arestas da ironia dão à paródia a sua dimensão crítica ao manter a diferença na similaridade. As práticas corporais, que antes naturalmente eram como de menino e de menina, trazendo um binômio que enrijece a vida, agora passam a ser, pouco a pouco, entendidas como efeito, como produção. Surge no corpo dissidente que antes era gritado incapaz e que agora tem impressa a desconstrução de preceitos naturalizados. O que aparece no corpo abjeto passa a ser visto como força disruptiva, força queer que se faz resistência. Esse status performativo traduz a noção de coabitação, indispensável às pedagogias que fissuram. O currículo cultural assume-se como proposta contrassexual a fim de desestabilizar e invalidar o sistema heterocentrado. É uma paródia irônica que escancara limites e se manifesta nos corpos-resistência materializados e experimentais.

Após leituras, diálogos com companheiros e companheiras de luta, percebi que o currículo cultural atende meus anseios, me leva a acreditar e me dá ferramentas. As situações didáticas, os relatos dos colegas, os encontros do GPEF, fortaleceram-me para construir uma educação pública de qualidade, potencializando as diferenças. Permite-me estar sensível às minorias, às práticas marginalizadas e silenciadas. O currículo cultural é o sopro diário que necessito para seguir em frente e fazer uma outra educação. (Relato $12^{12}$, p. 8).

${ }^{12}$ Ver Araújo (2019). 
Quais seriam, então, as possibilidades de um currículo que se pretende ser contrassexual? Como ele pode atender aos anseios de profissionais comprometidas/ os com a formação de sujeitos solidários? Como pensar em ações didáticas que permitam que os sujeitos relatem a si mesmos; que criem enquadramentos que instauram condições para que o corpo abjeto deixe (mesmo que momentaneamente) de sê-lo; que não façam pensar na abjeção como falta, mas como um espaço densamente povoado por uma série de corpos que ficaram de fora da produção da inteligibilidade? Uma chuva de dúvidas, de incertezas. Todas elas condizentes com a proposta do currículo cultural: não se sabe como serão os caminhos trilhados em cada tematização, pois o início se dá em movimento, sem ambicionar um fim estático.

\section{INCERTEZAS}

Pensemos em corpos-ocupantes, em que a permanência nos espaços públicos e privados seja resistência, possibilidade contraproducente. Pensemos nas pequenas situações como abertura de novos caminhos. Pensemos na possibilidade de um corpo vivo que balance as estruturas. Abramos mão da sede por um ponto de chegada seguro, dos horizontes como objetivos a serem alcançados. Busquemos as possíveis aberturas, as fendas. Findemos o ano letivo deixando perguntas que movimentem, que propulsionem uma retomada da artistagem no fazer pedagógico, para, assim, permitir reverberar as afecções que surgiram a partir do contágio. Permitamo-nos o flagrante com os pensamentos duvidosos e aventureiros. Pensemos em propostas em que as diferenças sejam valorizadas e potencializadas, em que as vozes ecoem, em que corpos se movam, em que as culturas antes deixadas de lado estejam presentes, em que os corpos in transe não sejam boicotados. Isso é caos, é abrir mão do que foi ensinado sobre o que é a escola e o fazer docente. É abdicar do controle tão esperado daqueles corpos-crianças (que chegam sempre cheios de vida, de pulsões e que são interditados pela sede de controle e de organização). É acreditar que, no caos, podem surgir fagulhas criativas que impulsionem esses corpos falantes para caminhos outros. E sem a segurança de quais serão.

Não há certezas na contrassexualidade. Não há vontade de fixação. Não há vislumbre de uma cartilha com indicações ou métodos de como agir. Mas há um contrato parodístico e radicalmente irônico que, quando assinado, coloca os sujeitos em um enquadramento de permissibilidade de disrupção, de fuga, de incerteza. A dualidade neoliberal capitalística não só almeja, mas produz essa normalização, essa prescrição de como viver a vida, pois ela se alimenta da violência contra os corpos que ela mesma produz como dissidentes. Mas esses mesmos corpos, quando permitidos na escola, quando valorizados em suas diferenças, quando não marcados somente pelas violências que os atravessam, quando entendidos como potência, como performance prostética, podem dar (ou não) outros rumos à ansiedade disciplinadora da escola e da sociedade. Na repetição das práticas corporais tematizadas pelo professorado na escola, emerge o desmascaramento da naturalidade de tais práticas, da fixidez delas, da não possibilidade de mudança. Em cada dança, em cada luta, em cada ginástica, em cada brincadeira ou em esporte tematizados, em cada docente, em cada canto da escola, há a chance de borrar a norma, de produzir uma possibilidade outra de prática. Seria isso o currículo cultural contrassexual? Essa é uma pergunta que reflete a ambição ansiosa de produção de verdades. Permitamos, então, a possibilidade de sentir, de criar, por meio do encontro desses corpos falantes, formas disruptivas de viver. O que virá disso? Fica a questão a ser pensada no decorrer do fazer pedagógico de cada docente.

\section{FINANCIAMENTO}

O presente estudo não contou com apoio financeiro.

\section{CONFLITOS DE INTERESSE}

Não há conflitos de interesse.

\section{REFERÊNCIAS}

Araújo EC. Boxe no Capão [Internet]. São Paulo: Grupo de Pesquisas em Educação Física Escolar, Universidade de São Paulo; 2019 [citado 2021 Jun 2]. Disponível em: http:// www.gpef.fe.usp.br/relatos/eloa_01.pdf

Bonetto PXR. Pop, k-pop e dança tradicional do leque: quando apenas o reconhecimento da cultura corporal não basta [Internet]. São Paulo: Grupo de Pesquisas em Educação Física Escolar, Universidade de São Paulo; 2019a [citado 2021 Jun 2]. Disponível em: http://www.gpef.fe.usp.br/ teses/bonetto_11.pdf

Bonetto PXR. O samba na Educação Física escolar: na batucada dos nossos tantãs [Internet]. São Paulo: Grupo de Pesquisas em Educação Física Escolar, Universidade de São Paulo; 2019b [citado 2021 Jun 2]. Disponível em: http:// www.gpef.fe.usp.br/relatos/bonetto_13.pdf

Bonetto PXR, Neira MG. A escrita-currículo da perspectiva cultural da Educação Física: por que os professores fazem o que fazem? Rev Educ. 2019;44:1-23.

Butler J. Corpos que pesam: sobre os limites discursivos do "sexo". In: Louro GL, editor. O corpo educado: pedagogias da sexualidade. 2. ed. Belo Horizonte: Autêntica; 2001. p. 191-219.

Butler J. Problemas de gênero: feminismo e subversão da identidade. Rio de Janeiro: Civilização Brasileira; 2016.

Butler J. Alianças queer e política anti-guerra. Rev Bagoas. 2017;11(16):29-49.

Dornelles PG. Do corpo que distingue meninos e meninas na educação física escolar. Cad CEDES. 2012;32(87):187-98. http://dx.doi.org/10.1590/S0101-32622012000200005.

Eto J, Neira MG. Em defesa de uma teoria pós-crítica de Educação Física. Pensar Prát. 2017;20(3):580-92. http:// dx.doi.org/10.5216/rpp.v20i3.42732. 
Foucault M. Michel Foucault, uma entrevista: sexo, poder e a política da identidade. Verve. 2004;5:260-77.

Gomes CAO. Dançando na escola: do balé das meninas ao inseto dos infernos do funk [Internet]. São Paulo: Grupo de Pesquisas em Educação Física Escolar, Universidade de São Paulo; 2019 [citado 2021 Jun 2]. Disponível em: http://www.gpef.fe.usp.br/relatos/carlos_gomes_01.pdf

Irias EA. Carrinhos, Abayomi e artesanais: brinquedos na Educação Física [Internet]. São Paulo: Grupo de Pesquisas em Educação Física Escolar, Universidade de São Paulo; 2019 [citado 2021 Jun 2]. Disponível em: http://www.gpef. fe.usp.br/relatos/irias_04.pdf

Neira MG, Nunes MLF. Educação Física, currículo e cultura. São Paulo: Phorte; 2009.

Neves MR. Diferentes significações sobre o k-pop [Internet]. São Paulo: Grupo de Pesquisas em Educação Física Escolar, Universidade de São Paulo; 2019a [citado 2021 Jun 2]. Disponível em: http://www.gpef.fe.usp.br/relatos/ marcos_ribeiro_12.pdf

Neves MR. A gente corre pra quê? [Internet]. São Paulo: Grupo de Pesquisas em Educação Física Escolar, Universidade de São Paulo; 2019b [citado 2021 Jun 2]. Disponível em: http://www.gpef.fe.usp.br/teses/marcos_ribeiro_10.pdf

Neves MR, Neira MG. O currículo cultural da Educação Física em ação: efeitos nas representações culturais dos estudantes sobre as práticas corporais e seus representantes. Motrivivência. 2020;32(63):1-19. http:// dx.doi.org/10.5007/2175-8042.2020e76536.

Oliveira JL Jr, Neira MG. Significações dos estudantes sobre o currículo cultural da Educação Física. Rev Bras Ciênc Esporte. 2020;42:e2037. http://dx.doi.org/10.1590/ rbce.42.2019.093.

Preciado, P. B. Manifesto contrassexual: práticas subversivas de identidade sexual. São Paulo: n-1 edições; 2017.
Preciado, P. B. Testo Junkie: sexo, drogas e biopolítica na era farmacopornográfica. São Paulo: n-1 edições; 2018.

Rocha MAB, Tenório KM, Souza M Jr, Neira MG. As teorias curriculares nas produções acerca da Educação Física escolar: uma revisão sistemática. Rev Currículo sem Fronteiras. 2015;15:178-94.

Santos LA. "Se lutar é violência, por que a igreja do bairro ensina o jiu-jítsu?" [Internet]. São Paulo: Grupo de Pesquisas em Educação Física Escolar, Universidade de São Paulo; 2019 [citado 2021 Jun 2]. Disponível em: http:// www.gpef.fe.usp.br/teses/santos_02.pdf

Santos FN Jr, Quaresma VN. Transmutando as performances dos corpos: rebeldias e transgressões educacionais [Internet]. São Paulo: Grupo de Pesquisas em Educação Física Escolar, Universidade de São Paulo; 2019 [citado 2021 Jun 2]. Disponível em: http://www.gpef.fe.usp.br/ semef2018/Relatos/flavio_vitor.pdf

Silva WS Jr. O basquete nas diferentes narrativas [Internet]. São Paulo: Grupo de Pesquisas em Educação Física Escolar, Universidade de São Paulo; 2019 [citado 2021 Jun 2]. Disponível em: http://www.gpef.fe.usp.br/relatos/ silva_junior_02.pdf

Souza LRS, Augusto CN. Basquetebol: entre faltas, estratégias e relações de gênero [Internet]. São Paulo: Grupo de Pesquisas em Educação Física Escolar, Universidade de São Paulo; 2019 [citado 2021 Jun 2]. Disponível em: http:// www.gpef.fe.usp.br/relatos/leandro_cyndel_01.pdf

Torres AC, Quaresma FN, Santos FN Jr. Corpos In-transe: a ciranda e o funk no jogo por conhecimentos e afetos outros [Internet]. São Paulo: Grupo de Pesquisas em Educação Física Escolar, Universidade de São Paulo; 2019 [citado 2021 Jun 2]. Disponível em: http://www.gpef.fe.usp.br/ teses/torres_quaresma_santos_junior_01.pdf 


\title{
ERRATA: (Um) Currículo cultural contrassexual? Movimentos que possibilitam corpos em trânsito
}

\author{
Cyndel Nunes Augusto ${ }^{a}$ (D), Marcos Garcia Neira ${ }^{b *}$ (D) \\ aUniversidade de São Paulo, Faculdade de Educação, Programa de Pós-graduação em Educação. São Paulo, SP, Brasil. \\ bUniversidade de São Paulo, Faculdade de Educação, Departamento de Metodologia do Ensino e Educação Comparada, \\ Programa de Pós-graduação em Educação. São Paulo, SP, Brasil.
}

Devido a um erro honesto, o artigo "(Um) Currículo cultural contrassexual? Movimentos que possibilitam corpos em trânsito" (DOI https://doi.org/10.1590/rbce.43.e002221), publicado no periódico Revista Brasileira de Ciências do Esporte, vol. 43, 2021, e002221, foi publicado com um erro.

Na página 1, onde se lê:

Cyndel Augusto Nunes

Leia-se:

Cyndel Nunes Augusto

Os autores lamentam pelo erro. 